\title{
A DESMOTIVAÇÃO DO PROFESSOR EM SALA DE AULA THE TEACHER'S DEMOTIVATION IN THE CLASSROOM
}

\begin{abstract}
Aldirene Rodrigues Marcos ${ }^{1}$
Resumo: A finalidade deste artigo é descrever e analisar a desmotivação do professor em sala de aula, realidade que estamos vivenciando em nosso local de trabalho, que nos dias atuais os professores sentem-se desmotivados para empenhar suas atividades principalmente dentro de sala de aula. Portanto tem como objetivo entender os fatores que desmotivam os docentes a se empenharem em sala de aula na rede pública. É, sobretudo identificar os fatores que desmotivam o comprometimento do docente com a qualidade de ensino. Nesse contexto buscam-se informações da causa da desmotivação, que tem como base bibliográfica de estudos feitos por vários autores que afirmam a tamanha desvalorização desse profissional e que toda responsabilidade está imposta sobre si, e que não tendo o suporte da família sente grande dificuldade de desenvolver suas atividades em sala. Além dos fatores favorecer para o adoecimento, que são os fatores interno e externo, como a falta de uma formação continuada ou contínua, falta da participação da família na escola, falta de recursos pedagógicos, alunos indisciplinados, a falta de interesse dos alunos, salários baixos, o sistema burocrático, salas superlotadas a escassez de oportunidade de crescimento profissional e entre outros. É percebido que estes fatores vêm trazendo consequências e o professor sendo o único e responsável.
\end{abstract}

Palavras-chave: Professor, Desmotivação, Aprendizagem.

Abstract: The purpose of this article is to describe and analyze the teacher's demotivation in the classroom, a reality that we are experiencing in our workplace, that nowadays teachers feel unmotivated to engage their activities mainly within the classroom. Therefore, it aims to understand the factors that discourage teachers from engaging in the public school classroom. It is, above all, to identify the factors that discourage the commitment of the teacher to the quality of teaching. In this context, information on the cause of demotivation is searched, which is based on the bibliographic studies carried out by several authors who affirm the great devaluation of this professional and that all responsibility is imposed on him, and that without the support of the family, he feels great difficulty in develop their activities in the classroom. In addition to the factors favoring illness, which are the internal and external factors, such as the lack of continuing or continuing education, lack of family participation in school, lack of pedagogical resources, undisciplined students, lack of interest from students, low salaries, the bureaucratic system, overcrowded rooms the scarcity of opportunities for professional growth and among others. It is noticed that these factors have brought consequences and the teacher being the only and responsible ones.

Keywords: Teacher, Demotivation, Learning.

\section{Introdução}

\footnotetext{
${ }^{1}$ Mestra em Ciências da Educação pela Faculdad Interamericana de Ciências Sociales- PY. Email- aldy_rodrigues@hotmail.com
} 
Esta pesquisa é de uma analise dos argumentos e questionamentos de profissionais da educação os professores, sobre a desmotivação que acorre principalmente dentro de sala de aula, e tem como relevância a má qualidade no ensino. $E$ destacar os objetivos que tem levado a causa desta problemática.

A história da educação brasileira vem passando por período de transformações, ocasionando várias mudanças social e psicológica, devida a um avanço, das tecnologias e conhecimento, o docente não consegue acompanhar, a sobrecarga de tarefas impostas pelo sistema, com pouco tempo para planejar, muitas vezes as atividades cotidianas como ensinar a ler, a escrever, a contar envolvem o professor de tal maneira que ele não tem tempo para a análise e discussão da situação, causando algumas vezes a não aprendizagem dos alunos e a frustração do docente em não ter ensinado. $O$ professor sente desmotivado, ou ficando até doente. (GOUVEIA, 2011).

Surge uma tendência de racionalidade produtiva, pois o docente é pressionado para rapidamente resolver os problemas que emergem em seu ambiente de trabalho, envolvendo-se em situações que algumas vezes não sabe como resolver, nas quais o sentido ético e epistemológico fica submetido ao mercado econômico (PÉREZ GÓMEZ, 2001 apud TOZETTO, 2008).

Administrar o saber docente requer um cuidado em todos os detalhes e equilíbrio mental, para que possamos passar pela transformação sem ficarmos doentes, o professor e o primeiro a está bem físico e psicológico, ao ir para a escola, porque ele está contribuindo na construção de pessoas, para uma sociedade melhor.

Com as cobranças de todas as partes, direção supervisão, pais, coordenação tendo que solucionar vários problemas ocorridos no dia - a dia em sua profissão, o docente se sente incapaz incompetente, de impotência em meio das dificuldades para resolver as situações em sala de aula, O professor se sente cansado e exausto e frustrado, para dar continuidade em suas atividades, tendo que seguir um sistema educacional que deixa a desejar. Muita cobrança e pouco resultado.

Com essa pesquisa pretende-se identificar fatores produzidos pela Instituição ou ambiente escolar o que leva ao adoecimento dos profissionais, e despontando que os problemas mentais, são as causas, da falta de entusiasmo para o trabalho, que atinge má qualidade no ensino. 
A desmotivação está relacionada por fatores relevantes mais externoextrínsecos ao docente (modelo de escola burocrática, exigências da carreira docente, condições e excesso de trabalho, etc.) e menos de fatores motivacionais interiores/intrínsecos ao docente (criatividade pedagógica, relacionamento com alunos, reconhecimento do seu trabalho, etc.).

A desmotivação do professor causada, no entanto, na sua insatisfação para com as condições de trabalho e a falta de horizontes de valorização e desenvolvimento profissional.

Pensar sobre o importante papel que o docente exerce na formação do discente, leva a analisar a importância da qualificação destes profissionais que muitas das vezes são deixados de lado.

A desmotivação é um processo de uma junção de fatores estressante que acontece fora e dentro de sala, que o acumulo desses fatores acaba resultando em doença. Precisamos ficar atento a esses fatores.

\footnotetext{
Aponta esse olhar, com a questão da saúde do professor, que e de suma relevância, pois ele desempenha uma função das primordiais, que é a função social, sendo responsável pela formação intelectual, social e crítica do indivíduo. (GASPARINI, 2005.p, 189-199)
}

Contudo busca-se averiguar as informações e relatos da problemática, que tem a principio o motivo da causa da desmotivação dos professores em sua prática pedagógica e em sala de aula. A essa tão desordem causada pela falta de motivação aos professores devidos, há inúmeros acontecimentos que vem ocorrendo ao longo dos anos. Com mudanças muito rápidas, falta de recursos, salários baixos, a falta de uma formação continuada. Carregando um fardo sozinho, além de cumprir com suas atividades que é ensinar, cumprir o seu dever com as cobranças do sistema burocrático e tendo que lidar com alunos indisciplinados, que está são tarefa dos pais. Ficando um desgaste físico e psíquico levando o docente ao adoecimento. São vários os fatores que desmotivam os docentes, a se empenharem na busca de qualidade de ensino. É preciso capacitar o docente e ter toda estrutura organizacional que o motiva a empenhar-se na busca da melhor qualidade de ensino. A uma relação entre a escola e o professor. Cada professor empenha- se, em sala de aula de acordo com suas próprias experiências, porém o seu desempenho depende do ambiente escolar. Devido a essa problemática a educação fica comprometida em todos os setores, principalmente no que regem a aprendizagem, pois quanto o professor está desmotivado o aluno se torna desmotivado também, tendo baixo 
rendimento escolar, as organizações educacionais sempre solicitando uma educação de qualidade.

A proposta desse trabalho que como professora no segundo ciclo do ensino do ensino fundamental, em uma escola da rede municipal, vivencio todos os dias, como está caminhando educação brasileira. Percebe-se a péssima qualidade de ensino causada por vários fatores que desmotivam os docentes se empenharem, educação básica, a qualidade de ensino na rede pública brasileira é ruim, desigual e estagnada. O Plano Nacional de Educação prevê a análise de aspectos que podem captar a eficiência de cada escola - como a formação dos professores, a localização da escola, o perfil dos alunos e o envolvimento da comunidade. "São fatores que não estão voltados apenas ao aprendizado do aluno, mas acabam influenciando a qualidade do ensino". O professor é considerado o responsável, porém este recebe influência de todo sistema (PNE, 2014).

Que por traz do cenário há uma realidade, que as políticas públicas não querem ver ou simplesmente, esconde-se.

\section{Metodologia}

Este artigo tem como pesquisa, fonte bibliográfica desenvolvido com materiais elaborados livros artigos sites, é também uma pesquisa descritiva "expõe características de determinada população ou de determinado fenômeno.

" A evidência obtida por meio de uma pesquisa quantitativa através analise e relatos. Com coerência e coesão com foco dos argumentos do que foram estruturados antes de serem aplicadas. Desenvolvendo o uso combinado e sequencial de uma fase de pesquisa quantitativa seguida de uma fase qualitativa, ou vice-versa. A combinação metodológica é considerada uma forma robusta de se produzir conhecimentos, uma vez que se superam as limitações de cada uma das abordagens tradicionais (qualitativa e quantitativa). Há uma corrente internacional que defende sua fusão para a produção de pesquisas mais robustas, por meio da mistura de métodos ou pesquisa triangular.

Para Zanelli (2002, p. 83), a "credibilidade de uma pesquisa consiste na articulação da base conceitual e de adotar critérios rigorosos no uso da metodologia". Esse trabalho tem como procedimentos de identificar o motivo da má qualidade de ensino, e os fatores que ocorrem com as mudanças e suas consequências. A pesquisa obteve como métodos quantitativos Conforme (GIL, 
1999; LAKATOS; MARCONI; 1993), fornecem bases lógicas, com um aprofundamento exaustivo de um ou mais objeto de maneira que se permita o seu amplo e detalhado conhecimento. Porém com base na pesquisa, as ferramentas que serão utilizadas no detalhamento do trabalho, buscando despontar à problemática.

\section{REFERENCIAL TEÓRICO}

Saviani (2009) Apresenta que a "educação oficial no Brasil começa em 15 de outubro de 1827, aspectos históricos e teóricos do problema no contexto brasileiro" em seis períodos, começando por "Ensaios intermitentes de formação de professores, quando foi promulgada a Lei das Escolas das Primeiras Letras". Durante o período colonial com iniciou nos colégios jesuítas, passando pelas aulas régias (implementadas pela Reforma Pombalina, até os cursos superiores criados a partir de João VI de 1808).

No segundo período denominado por expansão do padrão das Escolas Normais (1890-1932). Ficou marcado nas diversas Províncias, cujo marco inicial foi a Reforma Paulista da Escola Normal, tendo como anexo a escola modelo.

Terceiro período foi marcado pela "Organização dos Institutos de Educação (1932 a 1939) ". Destaque são as reformas de Anízio de Teixeira no Distrito federal em 1832, e de Fernando de Azevedo em São Paulo em 1833, ambos sobre inspiração do Ideário da Escola Nova.

Quarto período, o qual se caracterizou pela "Organização e implantação dos cursos de Pedagogia e de Licenciatura (1939-1971)". Os Institutos de Educação do Distrito Federal e de São Paulo, foram elevados ao nível Universitário, tornando a base dos estudos superiores de educação. A partir do Decreto 1.190 de 04 de abril de 1939, deu se a organização definitiva da faculdade de Filosofia da Universidade do Brasil. O quinto período foi caracterizado pela "Substituição da Escola Normal pela Habilitação Específica de Magistério (1971-1996)". As exigências para as adequações do campo curricular foram desencadeadas pelo golpe Militar em 1934. Mediante as mudanças da legislação do ensino, a Lei 5.692 modificou os ensinos primários e médios, por primeiro grau, nessas novas estruturas desaparecem as escolas normais e é instituída a habilitação especifica do $2^{\circ}$ grau para o exercício do magistério do $1^{\circ}$ grau.

O sexto e último período é denominado por Saviani (2009) "Advento dos Institutos de Educação e das Escolas Normais Superiores" (1996-2006). A Nova 
Lei das Diretrizes de Bases de Educação (93/94/96), entretanto, ela não correspondeu às expectativas e introduziu os cursos de Pedagogia e Licenciatura, tais características foram comtempladas pelas novas diretrizes curriculares de Pedagogia e homologadas em abril de 2006.

A partir de 1990 ocorrem às reformas educacionais no Brasil, entre essas, a implantação da gestão democrática nas escolas públicas, pela LDB, n. 9.394/96 que amplia o ano letivo de 180 dias para 200 dias, ou 800 horas anuais no ensino fundamental aumentando a carga dos professores que no plano legal o trabalho não restringe somente à sala de aula, mas que ele contempla ainda as relações com a comunidade, a gestão da escola, o planejamento do projeto pedagógico, a participação nos conselhos, entre outras funções. O que parece ser conquistas dos movimentos sociais torna-se frustação para os docentes que são mais cobrados e menos valorizados (ASSUNÇÃO, 2009).

A política pública educacional cria estratégias para a transformação na educação, devido a essas mudanças, o que mais são afetados são os docentes que estão ali dentro de sala, com os alunos, e como toda ação gera uma reação, um desconforto, o docente tendo que se adaptar de maneira muito rápida, que muitas das vezes não consegue acompanhar o processo, e este com o acumulo de atividades se sentindo exausto, e com o passar dos dias vão adoecendo.

São por demais conhecidas a mudanças vertiginosas ocorridas em todos os campos do conhecimento na nossa sociedade, (SANTOMÉ, 2006) com especial preponderância para as mudanças socioeducativas que incidem sobre as relações com a escola (LOPES, 2001). Esta vertigem gerou nos professores um sentimento de desajustamento face às novas exigências sociais e profissionais com que são confrontados (AFONSO et al., 1999). O ritmo acelerado de transformações da sociedade traduz-se num quadro escolar cada vez mais complexo que requer novas competências para o desempenho das funções atribuídas ao professor, exigência cada vez mais sentida como resultado da abertura da escola ao mundo e à modernidade (NÓVOA et al., 1995). A desresponsabilização da família pela educação e a "massificação do ensino" trazem responsabilidades acrescidas aos professores que antes estavam atribuídas aos pais (AFONSO et al., 1999), nomeadamente aquelas que advêm das dificuldades na relação com as famílias, principalmente com a diversidade cultural que caracteriza tais famílias (SANTOMÉ, 2006). 
A profissão docente já foi muito conceituada pela sociedade, uma vez que o professor era o centro da escola, visto como exemplo de postura pelas pessoas. Hoje vivemos numa sociedade marcada pelos avanços científicos e tecnológicos, e em meio a tantas mudanças sociais mudou-se significativamente essa percepção da sociedade em relação à profissão docente. Em decorrência disso, os profissionais da educação tiveram que se adequar para atender às novas exigências da sociedade moderna deixando de ser o centro que agora visa o aluno e mesmo a escola, ainda hoje permanecendo como a responsável pela sistematização do conhecimento, é formada por um corpo docente que nem sempre recebe a devida atenção no sentido de garantir melhores condições para exercício da profissão. Uma acentuada desvalorização social do professor enquanto profissional vem enfrentando os vários dilemas da profissão docente, como por exemplo, falta de estrutura, falta da participação da família na escola, baixa remuneração, desmotivação por parte dos alunos, não consegue os resultados esperados e se frustram diante seu ofício (COSTA et al., 2014).

A desmotivação acontece através de um conjunto de fatores estressores intrínsecos e extrínsecos, causados diariamente no ambiente escolar. Segundo Gil (2008), os papéis que o docente exerce são numerosos e diversificados a desmotivação está relacionada por fatores relevantes mais externo-extrínsecos ao docente (modelo de escola burocrática, exigências da carreira docente, condições e excesso de trabalho, etc.

Os professores estão envolvidos em uma teia de relações com pessoas, alunos pais funcionários e que diariamente tende a lidar com situações conflituosas devido aos problemas que aparecem simultaneamente em sua profissão, gerando vários tipos de estresses.

Observa se que os professores são extremamente demandados no seu trabalho e com frequência, pois depositaram toda a responsabilidade e compromisso pelo seu desempenho ao aprendizado dos alunos e da escola (Oliveira, 2006). Segundo Lüdke e Boing (2007, p. 1.188), "as críticas externas ao sistema educacional cobram dos professores cada vez mais trabalho, como se a educação, sozinha, tivesse que resolver todos os problemas sociais".

Sabe-se que a qualidade de ensino é importante, e que o ambiente onde trabalhamos faz parte do contexto, e com o aumento das atividades diárias no trabalho, está deixando nas pessoas um desiquilíbrio entre vida pessoal e trabalho, o não gerenciamento entre os dois, ocasiona estresse entre outros 
problemas psíquicos. Nas últimas décadas, os registros de licenças do trabalho por motivos de saúde na categoria dos professores, em diferentes países, identificam a maior prevalência de distúrbios mentais quando comparados com os outros grupos de doenças comunicadas nas declarações médicas (ASSUNÇÃO, 2003; DIMITROV, 1991; ESTEVE, 1999). No entanto esgotamento profissional vem ocasionando grande preocupação, nas instituições governamentais educacionais na comunidade, nas empresas sindicais, que trás consequências prejudiciais nas organizações e interfere especialmente nas relações interpessoais.

Cada vez mais o ambiente profissional prioriza valores econômicos em detrimento dos humanos. Observa-se um aumento na frequência desses comportamentos em profissionais que levam atividades de trabalho adicional para casa, com sobrecarga de horas de trabalho, remuneração incompatível com o trabalho, divisão não equitativa das tarefas e dedicação excessiva as atividades que pouco acrescentam à carreira (CAMPOS, 2008).

O professor é na verdade uma das profissões mais importante, não existe nenhuma profissão, que não tenha primeiro passado pelo professor, o professor é vítima de um sistema educacional, que não quer reconhecer a sua tamanha grandeza que ele exerce na sociedade.

. Estudo realizado em Hong Kong (CHAN, 2003) também mostrou que a profissão de ensinar é altamente estressante. Aproximadamente um terço dos professores pesquisados apresentou sinais de estresse e burnout entre os principais problemas de saúde. Quanto a esses, Kagan (1989) identifica cinco categorias que agrupam os fatores potencialmente estressantes no ambiente ocupacional da escola:

a) A humanização por parte do apoio administrativo (percebem que 0 diretor tem pouca consideração pelos problemas da sala de aula);

b) a relação com os alunos (sentimento de incapacidade para motivar ou controlar os alunos);

c) a relação com os colegas (percebem animosidade na relação com os colegas e distribuição desigual das tarefas entre os pares);

d) excesso de trabalho (percebem excesso de expectativa da gestão quanto ao volume de tarefas a serem realizadas por eles);

e) insegurança financeira (salários inadequados e discrepantes em face do grau de responsabilidade da sua missão). 
Nóvoa (1995) afirma que a formação profissional dos professores é repleta por lutas e conflitos, já que muito dos problemas vividos hoje na educação tem suas raízes nos problemas enfrentados pela profissionalização docente ao longo de sua história.

São visíveis, os problemas que o professor vem enfrentando, que muita das vezes não sabe mais como atuar em sala de aula, em decorrência das mudanças ocorridas no cenário educacional e da falta de interesse do aluno, o profissional precisa se manter atualizado, bem como desenvolver uma aprendizagem permanente para poder ser capaz de acompanhar essas transformações.

Compreende-se, a educação tem muito para ser melhorada e que uma delas é que os pais não estão tendo as devida responsabilidades com os seus filhos, não cobram as tarefas feitas, nem perguntam sobre as atividades ou olhem seus cadernos, professores reclamam que por mais que eles se esforcem se não estiver a ajudar da família o ensino fica comprometido. Como afirma esteve (1995), a família que deveria ser a primeira base da educação da criança, porém este está afastando-se dessa responsabilidade, exigindo-a do professor.

\begin{abstract}
A família tem que está atrelada com a escola, ambas só terão sucesso se caminharem para um mesmo objetivo que é a aprendizagem do aluno. A família e a escola constituem os dois principais ambientes de desenvolvimento humano nas sociedades ocidentais contemporâneas. Assim, é fundamental que sejam implementadas políticas que assegurem a aproximação entre os dois contextos, para que juntos possam reconhecer que a aprendizagem é compromisso de todos (DESSEN e POLÔNIA, 2007 p, 21-32).
\end{abstract}

A educação é compromisso de todos, precisa criar leis que incentiva a participação de um todo, principalmente escola e família e professor, sem essa união o ensino fica defasado, longe para ser um ensino de qualidade.

Como vemos estamos cercados desde emaranhados de fatores estressores que tem levado a este profissional cada vez mais, o aumento com os laudos médicos e afastamento, outros readaptados por problemas psíquicos. Isso nos faz refletir como os governantes não estão preocupados com a educação em si, se fala tanto em uma educação de qualidade, como podemos ter uma educação de qualidade se os profissionais estão muitas das vezes trabalhando doentes. Com a grande desvalorização de todas as esferas com este profissional que sempre doou a virtude que é de ensinar, com ele está a chave que abre todas as portas em rumo a realização de um sonho. Porém o 
mesmo carregando um sentimento de dever não cumprido, a não realização profissional o desrespeito da sociedade. Mesmo desmotivado, trabalha em função de transpor conhecimentos e saberes, para as pessoas se tornarem cidadãos melhores.

\section{Considerações finais}

No Brasil, a elaboração de políticas pública educacionais e caracterizadas por um abstracionismo, pedagógico que busca soluções para melhorar a qualidade de ensino, e não comtempla a realidade da escola. Um cenário, o profissional com longas jornadas de trabalho, a falta de recursos baixos salários é uma progressiva desvalorização social. A má formação dos profissionais, e uma das causas do fracasso em sala de aula, pois a carência de bagagem cultural que o docente possui sobre como ensina e como aprende, contribui para uma prática incoerente, as ações realizadas, pelo professor em sala de aula, que vem a ser o resultado das experiências e o resultado da qualidade de ensino.

Porém os governantes se falam em educação, mas este não vivencia a realidade em sala de aula, que devido um sistema que coloca toda a responsabilidade e compromisso no professor, este a cada dia vem ficando desmotivado e muitos estão ficando doentes. Uma educação falida que, enquanto a educação não for prioridade, e ter se consciência que tem que ter a participação de um todo, principalmente da família, vão se tornando um caos.

\section{Referências}

ASSUNÇÃO, A. Á.; OLIVEIRA, D. A. Intensificação do trabalho e saúde dos professores. Educação \& Sociedade, v. 30, n. 107, p. 349-372, 2009.

ASSUNÇÃO, A. A. Saúde e condições de trabalho nas escolas públicas. Reformas educacionais na América Latina e os trabalhadores docentes. Belo Horizonte: Autêntica, 2003. P. 87-102. 
AFONSO, A, J. Estado, mercado, comunidade e avaliação: esboço para uma (re) articulação crítica. Educação \& Sociedade, Campinas, v.20, n. 69, p.139-164,1999.

CAMPOS, C. V. de A.; MALIK, A. M. Satisfação no trabalho e rotatividade dos médicos do Programa de Saúde da Família. Revista de Administração Pública, n.1, v. 1, 2008.

COSTA, F. P., Silva, M. P., Bessa, V. P., \& Caldas, I. P. A história da profissão docente: Imagens e autoimagens. Universidade do Estado do Rio Grande do Norte, Brasil, 2014.

CHAN, F.T.S. Performance, Technology, v. 21, p. 534-548, 2003.

DESSEN, M. A.; POLONIA, A. C. A família e a escola como contextos de desenvolvimento humano. Paidéia, v. 17, n. 36, p. 21-32, 2007.

DIMITROV, I. Neurological morbidity in teachers. Folia Medica Plovdiv, v. 33, n. 3, p. 28- 35, 1991.

ESTEVE, J. M. Mal-estar docente. Barcelona: Paidós, 1999.

GASPARINI. et.al . O professor e as condições de trabalho e os efeitos de sua Saúde. Educação e Pesquisa; 31:189-199. 2005.

GIL, A. C. Didática do ensino superior. São Paulo: Atlas, 2008.

GOUVEIA, M. C. Mestre: profissão o professor (a)-processo de profissionalização docente na província mineira no período imperial. Revista Brasileira de História da Educação, v. 1, n. 2, p. 27-45, 2011.

LAKATOS, E.M.; MARCONI, M.A. Fundamentos de metodologia científica. São Paulo: Atlas, 1993.

NÓVOA, A. A 'nova' centralidade dos professores: do excesso dos discursos à pobreza das práticas. 1999. Disponível em: <https://repositorio.ul.pt/bit stream/10451/684/1/211 44_ISSN1517-9702.pdf>. Acesso em: 15 jan. 2019.

NÓVOA, A. On history, history of education, and history of colonial education. Pedagógica Histórica, v. 31, n. 1, p. 23-64, 1995.

PNE, 2014 _ Entrevista: novos desafios para a educação brasileira. Revista Retratos da Escola, Brasília, v.8, n.15, p.231-248, jul./dez.2014.

SAVIANI, D. Formação de professores: aspectos históricos do problema no contexto brasileiro. Rev. Bras. Educ., v.14, n. 40, p. 143-155, 2009.

SANTOMÉ, A desmotivação dos professores. Mangualde: Edições, Pedago Ltda, 2006.

SILVA, D. N. A desmotivação do professor em sala de aula, nas escolas públicas do município de São José dos Campos-SP. 2012. p.51. Trabalho de Conclusão de Curso (Especialização em Gestão Pública Municipal), Universidade Tecnológica Federal do Paraná Campus Curitiba, 2012.

SILVA, M. E. P. B.: Por que sofrem os professores? Estudos e Pesquisas em Psicologia, 6(1), 89-98. 2006.

TOZETTO, S.S. Mudanças nos saberes na perspectiva de professoras dos anos iniciais do ensino fundamental face à implantação de ações políticas educacionais no município de Ponta Grossa - PR. Araraquara, SP. p. 258, 2008.

ZANELLI, J. C. Pesquisa qualitativa em estudos da gestão de pessoas. Estudos de Psicologia, v. 7, p. 79 - 882002. 
